\title{
Hyperinsulinemia enhances interleukin-17-induced inflammation to promote prostate cancer development in obese mice through inhibiting glycogen synthase kinase 3-mediated phosphorylation and degradation of interleukin-17 receptor
}

\author{
Sen Liu ${ }^{1, *}$, Qiuyang Zhang ${ }^{1, *}$, Chong Chen ${ }^{1}$, Dongxia $\mathbf{G e}^{1}$, Yine Qu ${ }^{1}$, Rongyi Chen ${ }^{2}$, \\ Yi-Ming Fan ${ }^{2}$, Nan $\mathrm{Li}^{2}$, Wendell W. Tang ${ }^{3}$, Wensheng Zhang ${ }^{4}$, Kun Zhang ${ }^{4}$, Alun R. \\ Wang $^{5}$, Brian G. Rowan ${ }^{1,6,7}$, Steven M. Hill1,6, Oliver Sartor ${ }^{6,8,9}$, Asim B. Abdel-Mageed ${ }^{6,8}$, \\ Leann Myers ${ }^{10}$, Qishan Lin ${ }^{11}$, Zongbing You ${ }^{1,6,7,12}$ \\ ${ }^{1}$ Department of Structural and Cellular Biology, Tulane University, New Orleans, LA 70112, USA \\ ${ }^{2}$ Department of Dermatology, Affiliated Hospital of Guangdong Medical College, Zhanjiang, Guangdong 524001, China \\ ${ }^{3}$ Department of Pathology, Ochsner Clinic Foundation, New Orleans, LA 70130, USA \\ ${ }^{4}$ Department of Computer Science and Biostatistics Facility of RCMI Cancer Research Center, Xavier University of Louisiana, \\ New Orleans, LA 70125, USA \\ ${ }^{5}$ Department of Pathology and Laboratory Medicine, Tulane University, New Orleans, LA 70112, USA \\ ${ }^{6}$ Tulane Cancer Center, Louisiana Cancer Research Consortium, Tulane University, New Orleans, LA 70112, USA \\ ${ }^{7}$ Tulane Center for Stem Cell Research and Regenerative Medicine, Tulane University, New Orleans, LA 70112, USA \\ ${ }^{8}$ Department of Urology, Tulane University, New Orleans, LA 70112, USA \\ ${ }^{9}$ Department of Medicine, Tulane University, New Orleans, LA 70112, USA \\ ${ }^{10}$ Department of Biostatistics and Bioinformatics, Tulane University, New Orleans, LA 70112, USA \\ ${ }^{11}$ Proteomics/Mass Spectrometry Facility, University at Albany, Rensselaer, NY 12144, USA \\ ${ }^{12}$ Department of Orthopaedic Surgery and Tulane Center for Aging, Tulane University, New Orleans, LA 70112, USA \\ *These authors contributed equally to this work
}

Correspondence to: Zongbing You, e-mail: zyou@tulane.edu

Keywords: hyperinsulinemia, obesity, prostate cancer, interleukin-17, GSK3

Received: December 02, 2015

Accepted: January 29, 2016

Published: February 10, 2016

\section{ABSTRACT}

Interleukin-17 (IL-17) plays important roles in inflammation, autoimmune diseases, and some cancers. Obese people are in a chronic inflammatory state with increased serum levels of IL-17, insulin, and insulin-like growth factor 1 (IGF1). How these factors contribute to the chronic inflammatory status that promotes development of aggressive prostate cancer in obese men is largely unknown. We found that, in obese mice, hyperinsulinemia enhanced IL-17-induced expression of downstream proinflammatory genes with increased levels of IL-17 receptor A (IL-17RA), resulting in development of more invasive prostate cancer. Glycogen synthase kinase 3 (GSK3) constitutively bound to and phosphorylated IL-17RA at T780, leading to ubiquitination and proteasome-mediated degradation of IL-17RA, thus inhibiting IL-17-mediated inflammation. IL-17RA phosphorylation was reduced, while the IL-17RA levels were increased in the proliferative human prostate cancer cells compared to the normal cells. Insulin and IGF1 enhanced IL-17-induced inflammatory responses through suppressing GSK3, which was shown in the cultured cell lines in vitro and obese mouse models of prostate cancer in vivo. These findings reveal a mechanism underlying the intensified inflammation in obesity and obesityassociated development of aggressive prostate cancer, suggesting that targeting GSK3 may be a potential therapeutic approach to suppress IL-17-mediated inflammation in the prevention and treatment of prostate cancer, particularly in obese men. 


\section{INTRODUCTION}

Interleukin-17 (IL-17) family of cytokines includes IL-17A, IL-17B, IL-17C, IL-17D, IL-17E, and IL-17F [1]. There are five receptors, namely, IL-17 receptor A (IL-17RA), IL-17RB, IL-17RC, IL-17RD, and IL-17RE. IL-17RA forms functional heterodimers with IL-17RB (for cytokine IL-17E), IL-17RC (for cytokines IL-17A, IL-17F, and IL-17A/IL-17F heterodimer), IL-17RD (for an unknown ligand), or IL-17RE (for cytokine IL-17C) [2]. IL-17B and IL-17E (also known as IL-25) both bind to IL-17RB [3], and their competition for IL-17RB binding leads to functional antagonism between IL-17B and IL-17E [4]. IL-17A and IL-17F are secreted by T helper $17\left(\mathrm{~T}_{\mathrm{H}} 17\right)$ cells, $\gamma \delta \mathrm{T}$ cells, natural killer cells, and other immune cells [5]. IL-17A and IL-17F act on IL-17RA/ IL-17RC receptor complex to recruit nuclear factor- $\kappa \mathrm{B}$ (NF-אB) activator 1 (Act1) through SEFIR (similar expression to fibroblast growth factor genes, IL-17 receptors and Toll-IL-1R) domains that exist in IL-17RA, IL-17RC, and Act1 proteins. Act1 is an E3 ubiquitin ligase that activates tumor necrosis factor receptor-associated factor 6 (TRAF6) through lysine-63-linked ubiquitination [6]. The polyubiquitinated TRAF6 then activates transforming growth factor $-\beta$-activated kinase 1 (TAK1) and subsequently I $\kappa \mathrm{B}$ kinase (IKK) complex, resulting in activation of NF- $\kappa B$ pathway that initiates transcription of a variety of cytokines, chemokines and growth factors, such as $\mathrm{C}-\mathrm{X}-\mathrm{C}$ motif ligand 1 (CXCL1), $\mathrm{C}-\mathrm{C}$ motif ligand 20 (CCL20), IL-1 $\beta$, and $I L-6$ [7].

The IL-17 cytokine family, particularly IL-17A, plays important roles in a variety of autoimmune diseases, such as rheumatoid arthritis, psoriasis, multiple sclerosis, inflammatory bowel diseases, and systemic lupus erythematosus, and in host defense against bacterial, fungal, and parasitic as well as viral infections [7]. IL-17A promotes organ transplant rejection $[8,9]$. IL17A also promotes development of colon cancer [10-13], skin cancer [14, 15], breast cancer [16], prostate cancer $[17,18]$, lung cancer $[19,20]$, and pancreas cancer [21]. IL-17A may be involved with type 2 diabetes [22] and type 1 diabetes [23]. IL-17A may also promote artherosclerosis [24-26]. Many of the aforementioned conditions are commonly seen in obesity [27, 28]. Obesity is a chronic inflammatory state with increased serum levels of inflammatory cytokines TNF $\alpha$ and IL-6 [29]. Obese people have elevated serum levels of IL-17, insulin, and insulin-like growth factor 1 (IGF1) [29-31]. Insulin and IGF1 activate Akt to inhibit glycogen synthase kinase 3 (GSK3) activities [32], thus enhancing IL-17-induced expression of Cxcl1, Ccl20, and Il-6 [33, 34]. GSK3 inhibitors also enhance IL-17-induced gene expression $[33,35]$, whereas GSK $3 \beta$ overexpression or Akt inhibitors repress IL-17-induced gene expression [33-35]. These findings suggest that GSK3 mediates the crosstalk between IL-17 and insulin/IGF1 signaling pathways. Indeed,
$G s k 3 \alpha$ - or $G s k 3 \beta$-knockout abolishes the synergy between IL-17 and insulin/IGF1 signaling pathways [33, 34]. However, the molecular mechanisms underlying how GSK3 mediates the crosstalk are largely unknown. Here we demonstrate that GSK3 constitutively binds to and phosphorylates IL-17RA at T780, leading to ubiquitination and proteasome-mediated degradation of IL-17RA, thus inhibiting IL-17-mediated inflammation. Insulin and IGF1 enhance IL-17-induced inflammatory responses through suppressing GSK3, leading to enhanced prostate cancer formation in obese mice.

\section{RESULTS}

\section{Obese mice develop more invasive prostate cancers than lean mice}

Obese men are at increased risk of developing aggressive prostate cancer and dying of prostate cancer [36]. To simulate human prostate cancer development, we used a previously established mouse model that was crossbred between male mice with probasin promoter-driven Cre recombinase and female mice with floxed phosphatase and tensin homolog (Pten), thus Pten was conditionally knocked out in the mouse prostate, leading to prostate adenocarcinoma formation $[17,18,37]$. Starting at 3 weeks of age after weaning, male mice fed with standard chow diet (13.2\% calories by fat) for 27 weeks (i.e., at 30 weeks of age) had an average body weight of $34.9 \pm 2.5 \mathrm{~g}(n=10$, named as lean mice). In contrast, male mice fed with high-fat diet $(60 \%$ calories by fat) for 27 weeks (i.e., at 30 weeks of age) had an average body weight of $53.2 \pm 5.7 \mathrm{~g}(n=10$, named as obese mice), which was approximately $52 \%$ more than lean mice (Figure 1A, $P<0.001$ ). Obese mice had significantly more inguinal and epididymal fat tissues than lean mice (Figure 1B, $P<0.001$ ). The genitourinary (GU) block weight (a surrogate measurement of prostate tumor weight) was significantly heavier in obese mice than lean mice (Figure $1 \mathrm{C}, P<0.01$ ). Invasive (or microinvasive) adenocarcinomas were found in approximately $42 \%$ of the prostatic glands in obese mice, but only in $23 \%$ of those in lean mice (Figure 1D-1E, $P<0.001)$. These findings suggest that obese mice developed more invasive prostate cancers than lean mice, which is consistent with the published reports using Hi-Myc mouse model $[38,39]$. Plasma levels of leptin (obese mice $=0.9 \pm 0.4$ versus lean mice $=0.2 \pm 0.2 \mathrm{ng} / \mathrm{ml}$, $n=10, P<0.001$ ) and insulin (obese mice $=300.2 \pm$ 150.4 versus lean mice $=147.5 \pm 25.5 \mu \mathrm{IU} / \mathrm{ml}, n=10$, $P=0.015)$ were significantly higher in obese mice than lean mice. Plasma IL-17A (obese mice $=248.3 \pm$ 98.8 versus lean mice $=350.3 \pm 148.7 \mathrm{pg} / \mathrm{ml}, n=10$, $P=0.088$ ) and IGF1 (obese mice $=8.6 \pm 1.7$ versus lean mice $=6.9 \pm 2.2 \mathrm{ng} / \mathrm{ml}, \mathrm{n}=10, P=0.071$ ) levels were not significantly different between obese and 
lean mice. Obese mouse prostate tissues had increased levels of P-Akt, P-GSK3 $\alpha / \beta$, and Il-17-downstream genes such as Cxcl1, Ccl20, matrix metalloproteinase 7 (Mmp 7), Il-1 $\beta$, and $I l-6$ (Figure $1 \mathrm{~F}-1 \mathrm{H}$ ). Il-17ra and Il-17rc mRNA levels were not different between obese and lean mouse prostates (Figure 1G), but IL-17RA protein levels were higher in obese mouse prostates than lean mouse prostates (Figure $1 \mathrm{~F}$ ). P-I $\mathrm{B} \alpha \alpha$ levels were increased while $\mathrm{I} \kappa \mathrm{B} \alpha$ levels were decreased in obese mouse prostates (Figure $1 \mathrm{~F}$ ), indicating activation of $\mathrm{NF}-\kappa \mathrm{B}$ in obese mouse prostates. These findings suggest that increased IL-17RA levels in obese mouse prostates may be responsible for the enhanced expression of Il-17-downstream genes that promote formation of invasive prostate cancer in obese mice. IL-17RA level is also increased in human prostate cancer [40]. It was not known how IL-17RA protein level was increased in the absence of an increase at the $I l-17 \mathrm{ra}$ mRNA level, which prompted us to conduct further mechanistic studies as described below.

\section{GSK3 $\beta$ constitutively binds to and phosphorylates IL-17RA}

We and other investigators have shown that GSK3 represses IL-17A-induced gene expression [33-35]. We previously demonstrated that insulin and IGF1 activate Akt to inhibit GSK3 activities, thus enhancing IL-17A-induced expression of Cxcll, Ccl2O, and $\mathrm{Il}-6$ $[33,34]$. We found that in $G s k 3 \alpha$ - or Gsk3 $\beta$-knockout mouse embryonic fibroblasts (MEFs), the synergy between IL-17A and insulin/IGF1 is abolished, but both Gsk3 $\alpha$ and $G s k 3 \beta$-knockout enhance IL-17A-induced gene expression $[33,34]$. In our further analysis, we found that Gsk3 $\beta$-knockout enhanced not only gene expression induced by IL-17A and IL-17F (i.e., Cxcl1 and Ccl20), but also that induced by IL-17C (i.e., $I l-4$ and $I l-13$ ) and IL-17E (i.e., Ccl20, Il-5, and Il-13) (Figure 2A-2D), suggesting that GSK $3 \beta$ restricts the signaling of the whole IL-17 cytokine family at an apical level and likely at IL-17RA receptor as it binds to IL-17A/IL-17F, IL-17C, and IL-17E [2]. However, IL-17RA is not known as a GSK3 substrate. Act1, an IL-17RA and IL-17RC binding protein, is phosphorylated [41, 42]. To determine the candidate(s) of GSK3 substrate, we transfected human embryonic kidney 293 cells with Flag-tagged IL-17RA, V5-tagged IL-17RC, and/or HA-tagged Act1, and labeled the cells with $\left[{ }^{32} \mathrm{P}\right]$ orthophosphate. Immunoprecipitation (IP) was performed using anti-HA antibody to pull down Act1 and its binding partners IL-17RA and IL-17RC. After autoradiography to show ${ }^{32} \mathrm{P}$ labeling, the same blot was used to detect Flag-IL-17RA, V5-IL-17RC, and HA-Act1 by immunoblotting (IB). To our surprise, we found that only Flag-IL-17RA was strongly labeled with ${ }^{32} \mathrm{P}$ (Figure 3A-3D and Supplementary Figure S1A), which was reduced by calf-intestinal alkaline phosphatase (CIP) treatment (Supplementary Figure S1B). An algorithm analysis predicted that IL-17RA contained many potential phosphorylation sites including multiple GSK3 consensus sites (Supplementary Table S1). In 293 cells transfected with Flag-IL-17RA, anti-Flag IP pulled down GSK3 $\beta$ (Figure 3E), and further Co-IP assays confirmed binding of GSK $3 \beta$ to IL-17RA (Figure $3 \mathrm{~F}-3 \mathrm{G}$ ). To check if GSK3 was functional in IL-17RA phosphorylation, 293 cells were co-transfected with Flag-IL-17RA, HA-GSK3 $\beta$, or HA-GSK3 $\beta K 85 A$ (a kinase-dead mutant of GSK3 $\beta$ ), and labeled with $\left[{ }^{32} \mathrm{P}\right]$ orthophosphate, with or without $\mathrm{LiCl}$ (a GSK3 inhibitor) treatment. We found that $\mathrm{LiCl}$ treatment reduced ${ }^{32} \mathrm{P}$ labeling of Flag-IL-17RA, but overexpression of wild-type (WT) HA-GSK3 $\beta$ enhanced ${ }^{32} \mathrm{P}$ labeling of Flag-IL-17RA, while overexpression of kinase-dead HA-GSK3 $\beta$ K $85 \mathrm{~A}$ did not show any effects (Figure $3 \mathrm{H}$ ). Together, these data demonstrate that GSK $3 \beta$ constitutively binds to and phosphorylates IL-17RA.

\section{T780 is one of the IL-17RA phosphorylation sites}

To identify the phosphorylation sites of IL-17RA, we purified Flag-IL-17RA protein expressed in 293 cells. Mass spectrometry analysis of the purified protein identified 8 phosphorylation sites including S554, S629, S708, S726, T780, S792, S798, and S801, all of which are conserved between human and mouse except S708 and S726 (Supplementary Figure S2). To confirm these sites, we made IL-17RA mutants. Deletion of residues from 616 to $728(\Delta 616-728)$ or T780A mutation reduced ${ }^{32} \mathrm{P}$ labeling (Figure $4 \mathrm{~A}$ ), suggesting that there are multiple phosphorylation sites and T780 is one of them. To pinpoint the sites, we deleted the proximal intracellular 430 amino acids ( $\Delta 343-772)$ and mutated all 10 potential phosphorylation sites within the remaining $\mathrm{C}$-terminal 94 amino acids ( $\triangle 343-772$ M10) (Supplementary Figure S1C). $\Delta 343-772$ WT protein was labeled with ${ }^{32} \mathrm{P}$ that was reduced by CIP (Supplementary Figure S1D). $\Delta 343-772$ M10 protein was not labeled with ${ }^{32} \mathrm{P}$ (Figure 4B); however, when T780 was reversed to WT in the protein ( $\triangle 343-772$ M9T780), ${ }^{32} \mathrm{P}$ labeling re-appeared (Figure 4B), confirming that T780 is one of the phosphorylation sites.

\section{T780 is phosphorylated by GSK3 and is detectable with anti-P-IL-17RA (T780) antibodies}

Next, we generated rabbit polyclonal antibodies against a phosphopeptide (C-LTDPH ${ }_{\mathrm{p}}$ TPYEEEQ) in four rabbits, which were named as B1, B2, B3, and B4 antibodies (Supplementary Figure S1E). All of them recognized the phosphopeptide, but not the unphosphorylated peptide or CIP-treated phosphopeptide (Supplementary Figure S1F-S1G). WT peptide, but not the T780A mutant peptide, was phosphorylated by recombinant GSK $3 \alpha$ and GSK $3 \beta$ proteins in in vitro 
kinase assays (Figure 4C). B4 could detect WT Flag-IL-17RA, but not any mutants containing the T780A mutation (Figure 4D and Supplementary Figure S1H). B4 also detected endogenous P-IL-17RA in 293 and HeLa cells (Supplementary Figure S1I). B4 IP pulled down exogenous and endogenous P-IL-17RA, but not T780A-mutant IL-17RA (Figure 4E). These data demonstrate that T780 is phosphorylated by GSK3, which is detectable with anti-P-IL-17RA (T780) antibodies.

\section{Insulin reduces the levels of P-IL-17RA through suppressing GSK3}

AZD5363 (a pan-Akt inhibitor) can inhibit Akt, thus increasing GSK3 activity, whereas insulin can activate Akt to inhibit GSK3 activity [34]. AZD5363 increased the levels of exogenous P-IL-17RA in 293 cells and endogenous P-IL-17RA in HeLa cells
(Figure 5A and 5D). In contrast, insulin treatment reduced the levels of exogenous and endogenous P-IL-17RA, while increasing the levels of total exogenous IL-17RA (Figure 5A). Consequently, a combination of insulin and IL-17 treatment significantly enhanced IL-17-downstream gene expression, whereas AZD5363 inhibited this synergy in both 293-IL-17RA stable cells (Figure 5B and 5C) and HeLa cells (Figure 5E and 5F). These data suggest that insulin reduces the levels of P-IL-17RA through suppressing GSK3, leading to increased levels of total IL-17RA and IL-17 responsiveness.

\section{Phosphorylation of IL-17RA at T780 leads to its ubiquitination and proteasome-mediated degradation}

LiCl, a GSK3 inhibitor, reduced the levels of exogenous and endogenous P-IL-17RA, while increased
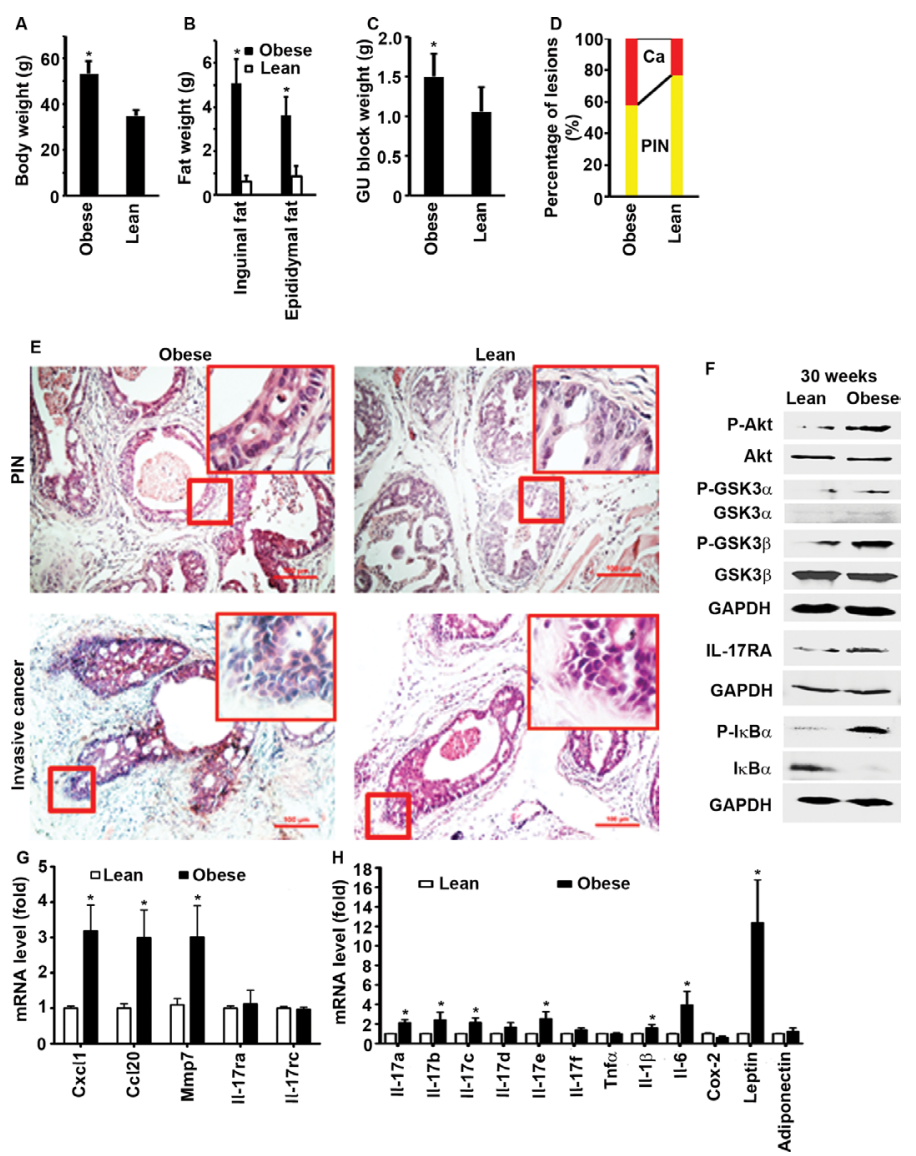

Figure 1: High-fat diet-induced obesity promotes prostate cancer formation in Pten conditional knockout mouse prostates. (A) Mouse body weight at age of 30 weeks. ${ }^{*} P<0.001$ (Student's $t$ test). (B) The tissue weight of inguinal fat and epididymal fat. ${ }^{*} P<0.001$ (Student's $t$ test). (C) The genitourinary (GU) block weight. ${ }^{*} P<0.01$ (Student's $t$ test). (D) Percentages of PIN and invasive cancer in dorsal, lateral, and ventral prostatic lobes. ${ }^{*} P<0.001$ (Kruskal-Wallis test). (E) Representatives of H \& E-stained dorsal prostatic lobes showing mouse prostatic intraepithelial neoplasia (PIN) and invasive (or microinvasive) adenocarcinomas; the red windows highlight the selected regions at x 400 magnification; scale bar, $100 \mu \mathrm{m}$. (F) Western blot analysis of the proteins isolated from the representative prostate tissues of obese and lean mice at age of 30 weeks. Anti-P-GSK $3 \alpha$ antibodies recognize Ser21 phosphorylation site and anti-P-GSK3 $\beta$ antibodies recognize Ser9 phosphorylation site. (G,H) qRT-PCR analysis of mRNA expression in lean and obese mouse prostates. ${ }^{*} P<0.05$ (one-way ANOVA). Data represent mean \pm standard deviation of 10 mice per group $(n=10)$. 
the total exogenous IL-17RA (Figure 6A). MG132, a proteasome inhibitor, increased the levels of both phosphorylated and total exogenous IL-17RA (Figure 6B). When treated with cycloheximide (CHX, a protein synthesis inhibitor), the total exogenous IL-17RA level decreased rapidly, while $\mathrm{LiCl}$ or MG132 inhibited the decrease (Figure 6C and 6D). These data suggest that phosphorylated IL-17RA undergoes proteasomemediated degradation. Further, degradation of $\Delta 343-772$ M9T780 protein was faster than $\triangle 343-772$ M10 protein (Supplementary Figure S3A-S3B). WT Flag-IL-17RA was ubiquitinated, the level of which was increased in the presence of MG132 (Figure 6E, lanes 3 versus 4); however, IL-17RA T780A mutant showed minimal ubiquitination even in the presence of MG132 (Figure 6E, lanes 5 versus 6). Further, WT IL-17RA, but not T780A mutant, was ubiquitinated with K48-linked ubiquitin (Figure 6F) and K63-linked ubiquitin (Supplementary Figure S3D). These data demonstrate that phosphorylation of IL-17RA at T780 leads to its ubiquitination and proteasome-mediated degradation, resulting in inhibition of IL-17-mediated inflammatory responses.

\section{Phosphorylation of IL-17RA is reduced in proliferative prostate cancer cells and keratinocytes}

IL-17-mediated inflammation plays important roles in human and mouse prostate cancers [17, 18, 40, 43, 44]. Human normal prostatic epithelium was stained highly positive for P-IL-17RA (Figure 7A-7C). Human prostatic intraepithelial neoplasia (PIN) was stained moderately positive for P-IL-17RA (Figure 7D-7F). In contrast, human prostate cancer was stained weakly positive for P-IL-17RA (Figure 7G-7I and Supplementary Figure $\mathrm{S} 4 \mathrm{~A}-\mathrm{S} 4 \mathrm{H})$. On the same tissue section containing both malignant and normal glands (identified by histology and presence of p63-positive basal cells), the malignant glands were stained weakly for P-IL-17RA but strongly for IL-17RA, whereas the normal glands were stained strongly for P-IL-17RA but weakly for IL-17RA (Supplementary Figure S4I-S4Q). Using the Allred scoring system [45], P-IL-17RA staining was significantly higher in human normal prostate and PIN than prostate cancer (Figure $7 \mathrm{~J}$ ). IL-17 also stimulates rapid proliferation of keratinocytes

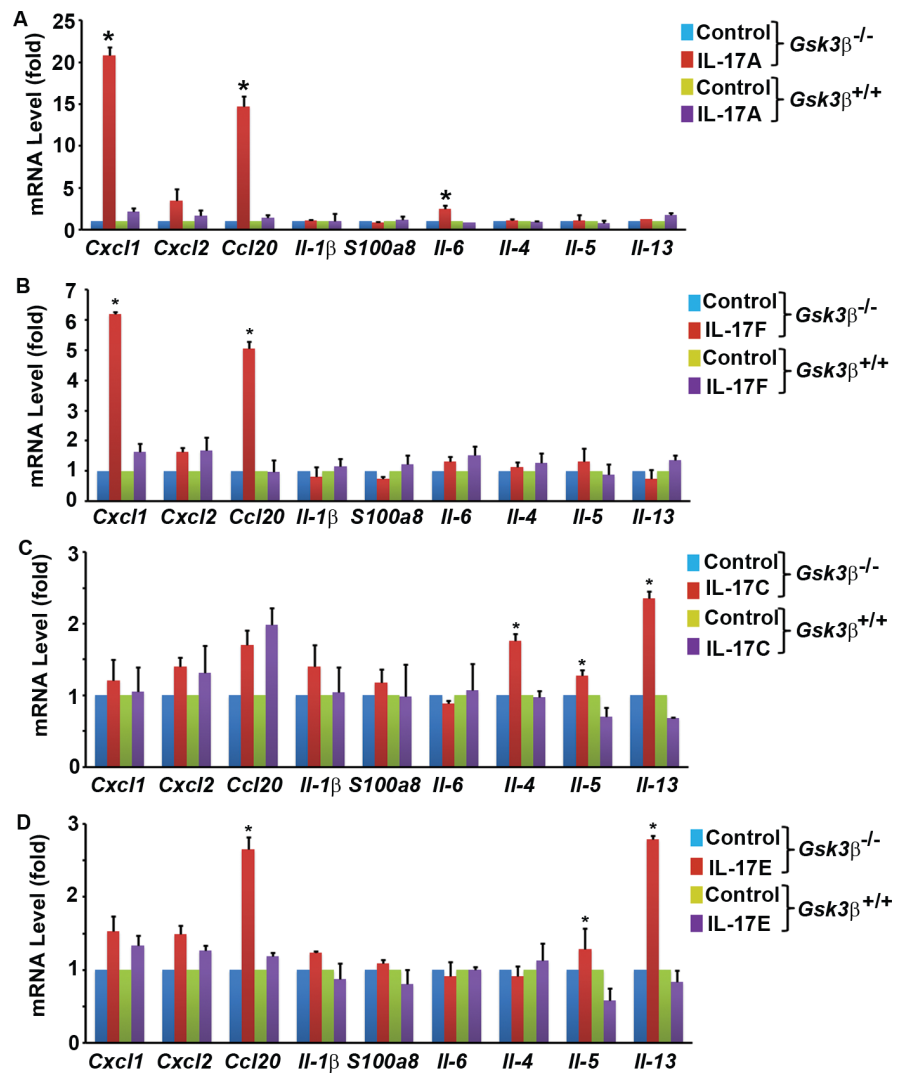

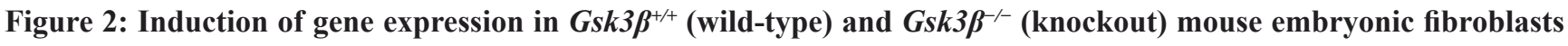
(MEFs) by IL-17 family cytokines. (A-D) MEFs were treated with $20 \mathrm{ng} / \mathrm{ml}$ mouse recombinant IL-17A (A), IL-17F (B), IL-17C (C), and IL-17E (D) for $2 \mathrm{~h}$. Gene expression was determined using qRT-PCR analysis. The levels of the control group (treated with phosphatebuffered saline) were taken as the basal levels. Data represent the mean \pm standard deviation of three independent experiments $(n=3)$; $* P<0.05$ (Student's $t$ test). 
in psoriasis [46]. In both human normal and psoriatic epidermis, the differentiated suprabasal keratinocytes were stained strongly positive for P-IL-17RA, whereas the proliferating basal keratinocytes were stained negative for P-IL-17RA (Supplementary Figure S5A-S5J). B4/Ki-67 double staining showed that Ki-67-positive keratinocytes were not stained by B4, while B4-positive keratinocytes were not stained by Ki-67 (Supplementary Figure S5D and S5J). In psoriatic epidermis, Ki-67-positive keratinocytes were stained negative for P-IL-17RA but positive for IL-17RA (Supplementary Figure S5K-S5P). These data demonstrate that the levels of P-IL-17RA are reduced while the levels of IL-17RA are increased in proliferative prostate cancer cells and keratinocytes, which may enhance IL-17 responsiveness.

\section{Phosphorylation by GSK3 is conserved in human and mouse IL-17RA}

Mouse P-IL-17RA levels were not assessable due to lack of anti-mouse P-IL-17RA antibodies. However, mouse peptide containing T779 (corresponding to human T780) was phosphorylated by recombinant GSK $3 \alpha$ and GSK3 $\beta$ (Supplementary Figure S6A-S6B). Purified full-length mouse IL-17RA was phosphorylated by recombinant GSK3 $\alpha$ and GSK3 $\beta$, which was very weakly cross-reactive with B4 antibodies (Supplementary Figure S6C), due possibly to the similarity between mouse and human epitopes and the high levels of phosphorylated mouse IL-17RA in the in vitro assays. However, B4 antibodies could not detect the endogenous levels of mouse P-IL-17RA (Supplementary Figure S6C, the control lane).

\section{DISCUSSION}

The present study shows that GSK3 binds to and phosphorylates IL-17RA at T780, leading to K48-linked ubiquitination and proteasome-mediated degradation of IL-17RA. Thus, GSK3 represses IL-17 signaling through reducing IL-17RA protein levels (Supplementary Figure S6D). This mechanism explains our previous observation that insulin and IGF1 enhance IL-17-induced gene expression $[33,34]$, as insulin and IGF1 can activate PI3K/Akt to suppress GSK3 activities (Supplementary Figure S6D). Obese people have elevated serum levels of IL-17, insulin, and IGF1 [29-31], as well as increased serum levels of inflammatory cytokines TNF $\alpha$ and IL-6 that are IL-17-downstream target genes. Our findings suggest that in obesity, insulin and IGF1 signaling pathway cross-talks with IL-17 signaling pathway through suppressing GSK3 activities, thus enhancing IL-17-mediated inflammation and contributing to the chronic inflammatory status commonly seen in obesity. In our obese animal model, increased insulin levels activate Akt to increase inhibitory phosphorylation of GSK $3 \alpha / \beta$, leading to reduced phosphorylation of IL-17RA and hence reduced ubiquitination and

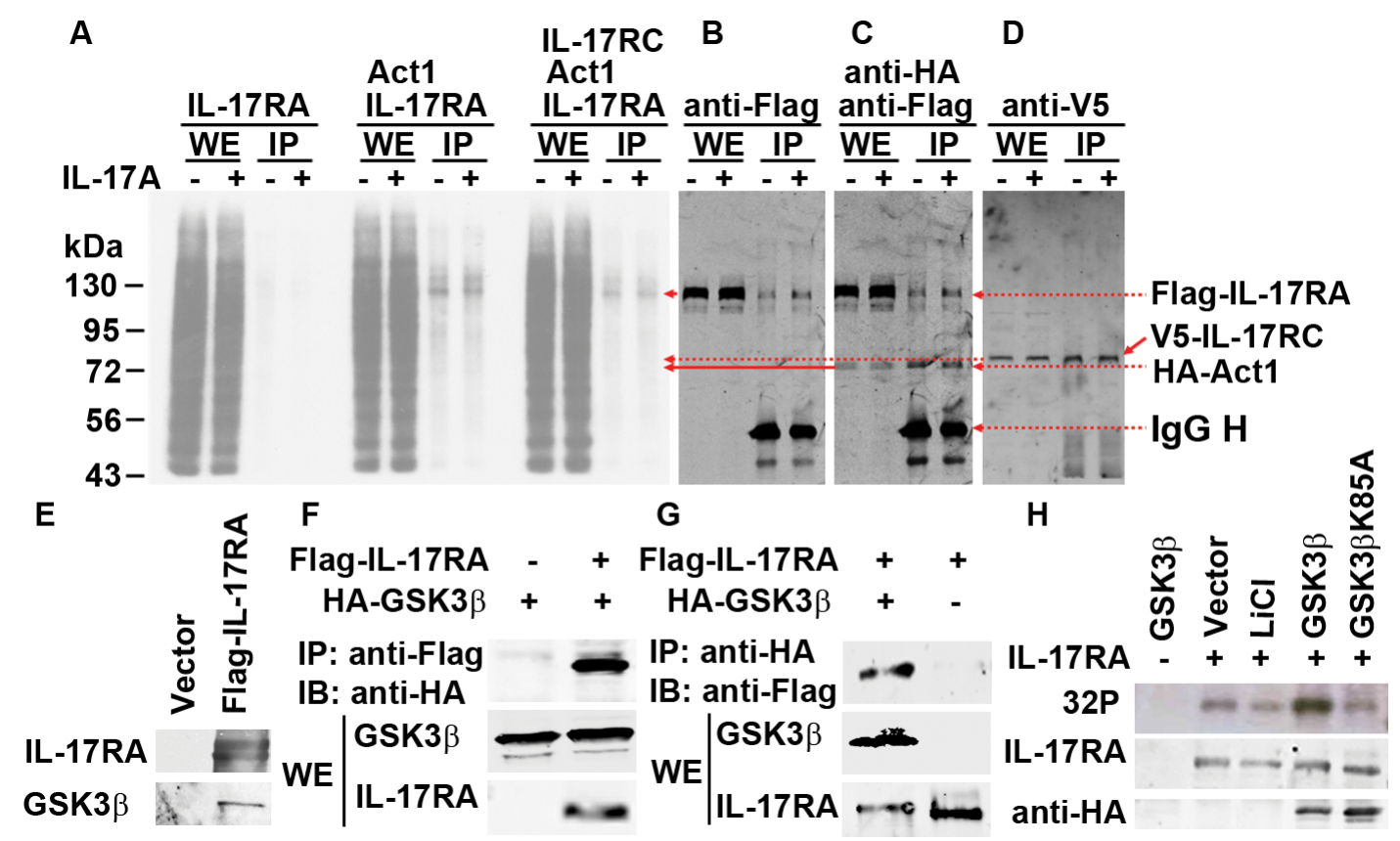

Figure 3: GSK3ß binds to and phosphorylates IL- 17RA. (A-D) 293 cells were co-transfected with Flag-IL-17RA, V5-IL-17RC, and HA-Act1, labeled with ${ }^{32} \mathrm{P}$ orthophosphate, and treated with $20 \mathrm{ng} / \mathrm{ml} \mathrm{IL-17A}$ for $20 \mathrm{~min}$; IP with anti-HA; autoradiography (A) followed by IB (B-D). (E) Anti-Flag IP followed by IB. (F-G) Co-IP of Flag-IL-17RA and HA-GSK3 $\beta$. (H) 293 cells were co-transfected with Flag-IL-17RA, WT HA-GSK3 $\beta$ or kinase-dead mutant HA-GSK3 $\beta$ K85A, labeled with ${ }^{32} \mathrm{P}$ orthophosphate, or treated with $20 \mathrm{mM}$ $\mathrm{LiCl}$ for $2 \mathrm{~h}$; autoradiography $\left({ }^{32} \mathrm{P}\right)$ followed by IB. WE, whole cell extract. 



Figure 4: GSK3ß phosphorylates IL-17RA at T780. (A-B) 293 cells were transfected with Flag-IL-17RA and its mutants and labeled with ${ }^{32} \mathrm{P}$ orthophosphate; autoradiography $\left({ }^{32} \mathrm{P}\right)$ followed by IB. (C) IL-17RA peptide phosphorylated at T780 (p-Peptide) was treated with CIP, while IL-17RA peptide with wild-type T780 (Peptide) or with mutant T780A (mut-Peptide) were treated with recombinant GSK3, followed with dot blot analysis using B4 antibodies. (D-E) Flag-IL-17RA, Flag-IL-17RAT780A mutant, or empty vector was transfected into 293 cells; HeLa cells were not transfected; IP with anti-Flag, B4 (+), or control IgG (-), followed by IB; *indicates endogenous P-IL-17RA. 
degradation of IL-17RA. Subsequently, IL-17RA protein levels are increased to enhance IL-17 responsiveness as evidenced by increased NF- $\kappa \mathrm{B}$ activation and enhanced expression of IL-17-downstream genes such as Cxcl1, Ccl20, Il-6, and Mmp7. The biological consequence is development of more invasive prostate cancers in obese mice than lean mice, which echoes the observation that obese men are at increased risk of developing aggressive prostate cancer [36].

To our best knowledge, this is the first study showing that IL-17RA is phosphorylated. It appears that there are multiple phosphorylation sites of IL-17RA, though we only focused on T780 residue. We presented several lines of evidence to confirm that T780 is phosphorylated by GSK3: first, ${ }^{32} \mathrm{P}$ labeling is reduced with T780A mutant IL-17RA compared to wild-type IL-17RA; second, reversal of $\Delta 343-772 \mathrm{M} 10$ (with all potential phosphorylation sites mutated) to $\Delta 343-772$ M9T780 (with only T780 reversed to wild-type) reinstalled ${ }^{32} \mathrm{P}$ labeling; third, T780 wild-type peptide, but not T780A mutant peptide, is phosphorylated by GSK $3 \alpha / \beta$; and fourth, wild-type, but not T780A mutant, IL-17RA is recognized by the antibodies against
A





B4

Exogenous

Endogenous

Flag (IL-17RA)
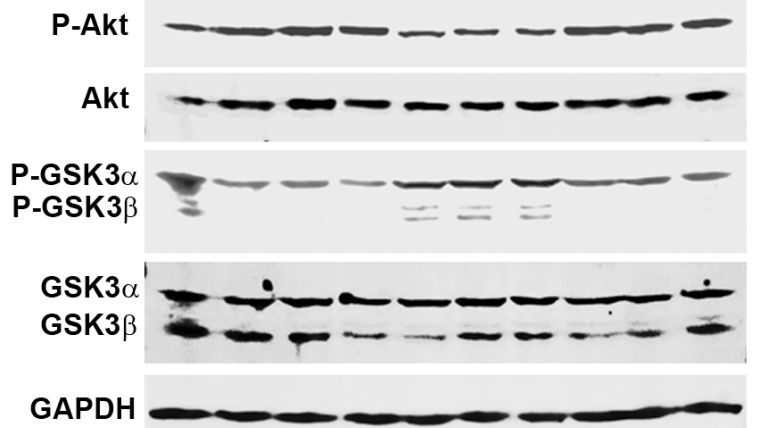

D
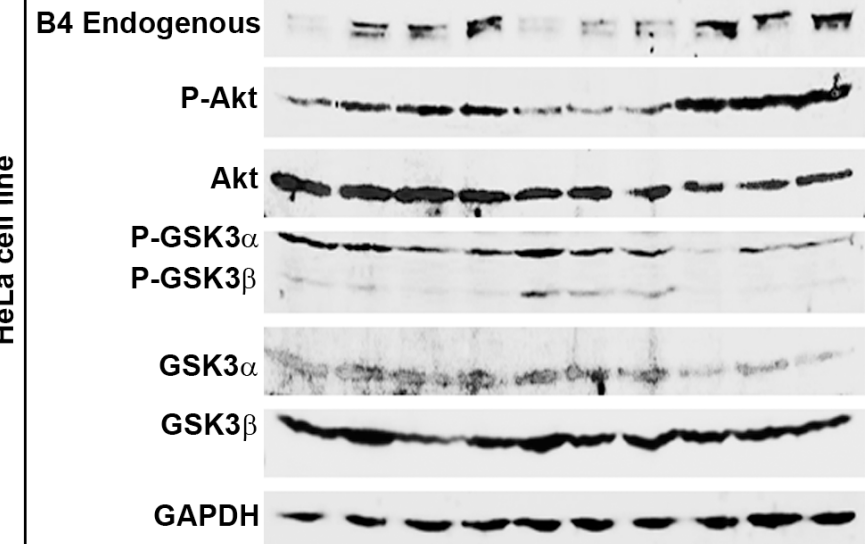

B



\section{家}

C


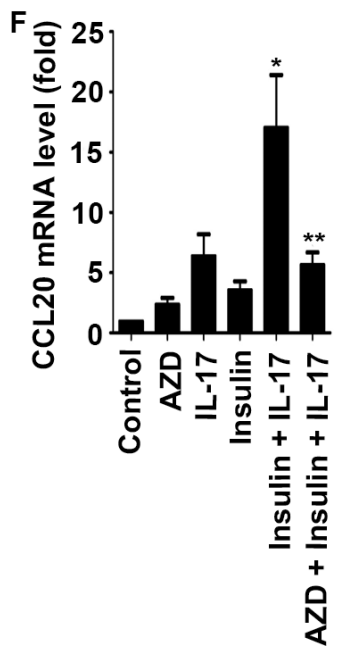

Figure 5: AZD5363 antagonizes insulin-induced enhancement of IL-17 responses through restoring IL-17RA phosphorylation. (A) and (D) 239 cells stably expressing Flag-IL-17RA (293-IL-17RA cell line) and HeLa cells were treated with $2 \mu \mathrm{M}$ AZD5363 (a pan-Akt inhibitor) and/or $50 \mathrm{ng} / \mathrm{ml}$ insulin for the indicated time periods; Western blot analysis was performed for the indicated proteins; exogenous, IL-17RA transfected into 293 cells; endogenous, endogenous IL-17RA expressed in 293 and HeLa cells.

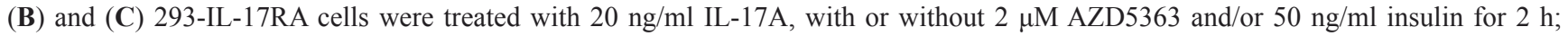
IL-17-downstream gene expression was determined using qRT-PCR analysis; ${ }^{*} P<0.05$ compared to each single treatment group; ${ }^{* *} P<0.05$ compared to the combined insulin and IL-17 treatment group (one-way ANOVA). (E) and (F) HeLa cells were treated with $20 \mathrm{ng} / \mathrm{ml}$ IL-17A, with or without $2 \mu \mathrm{M}$ AZD5363 and/or $50 \mathrm{ng} / \mathrm{ml}$ insulin for $2 \mathrm{~h}$; IL-17-downstream gene expression was determined using qRTPCR analysis; $* P<0.05$ compared to each single treatment group; ${ }^{*} P<0.05$ compared to the combined insulin and IL-17 treatment group (one-way ANOVA). Data represent the mean \pm standard deviation of three independent experiments $(n=3)$. 

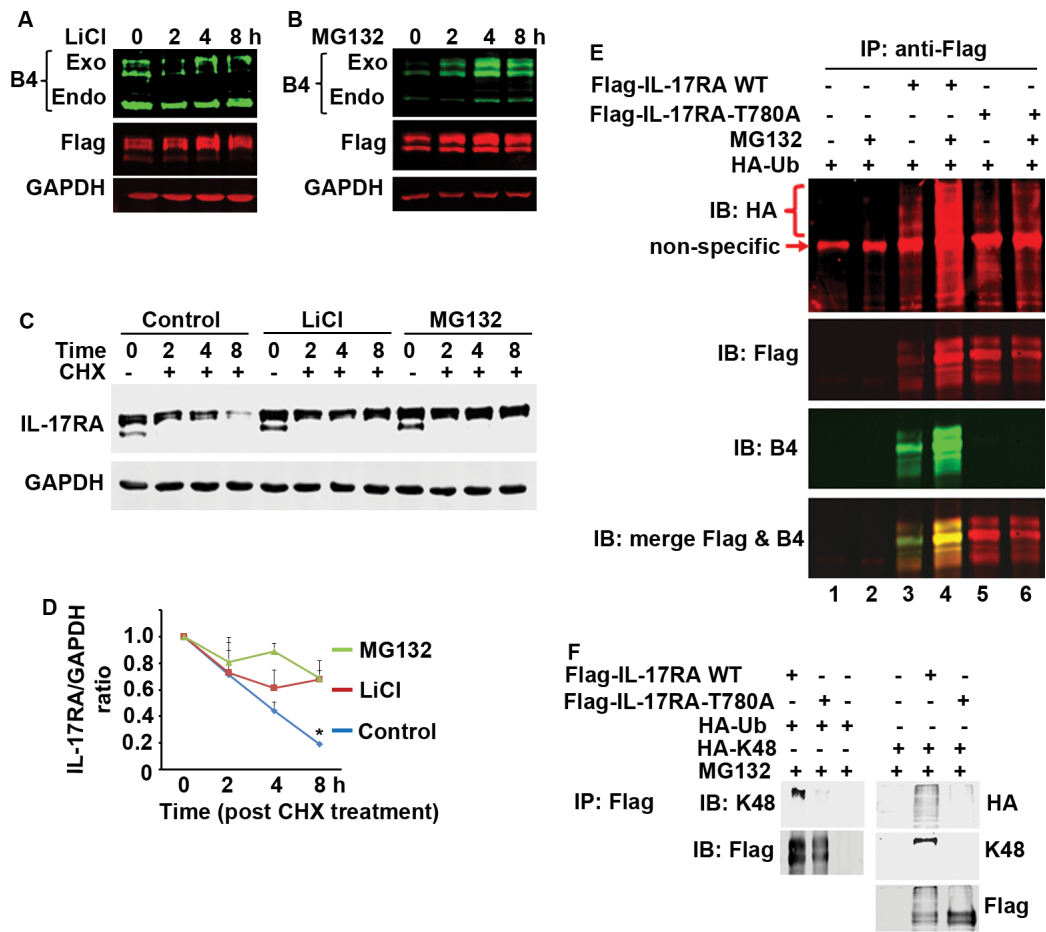

Figure 6: Phosphorylated IL-17RA is ubiquitinated and degraded by proteasome-mediated mechanism. (A-D) 293 cells stably expressing Flag-IL-17RA were treated with $20 \mathrm{mM} \mathrm{LiCl}$ or $10 \mu \mathrm{M}$ MG132, and/or $50 \mu \mathrm{g} / \mathrm{ml} \mathrm{CHX;} \mathrm{P-IL-17RA} \mathrm{was} \mathrm{detected} \mathrm{using}$ B4 and total exogenous IL-17RA was detected using anti-Flag; the levels of total exogenous IL-17RA (C) were normalized by the levels of GAPDH (D); exo, exogenously transfected IL-17RA; endo, endogenously expressed IL-17RA; $* P<0.05$ compared to LiCl and MG132 treated groups (Student's $t$ test). (E) Flag-IL-17RA and Flag-IL-17RA-T780A mutant were co-transfected with HA-tagged ubiquitin (HA-Ub), with or without $10 \mu \mathrm{M}$ MG132 treatment; non-specific, an unknown band detected by anti-HA antibodies, which was not IL-17RA or IgG heavy chain (see Supplementary Figure S3C). (F) Flag-IL-17RA and Flag-IL-17RA-T780A mutant were co-transfected with HA-tagged ubiquitin (HA-Ub) or K48-only ubiquitin (HA-K48), with $10 \mu \mathrm{M}$ MG132 treatment, followed by IP and IB.
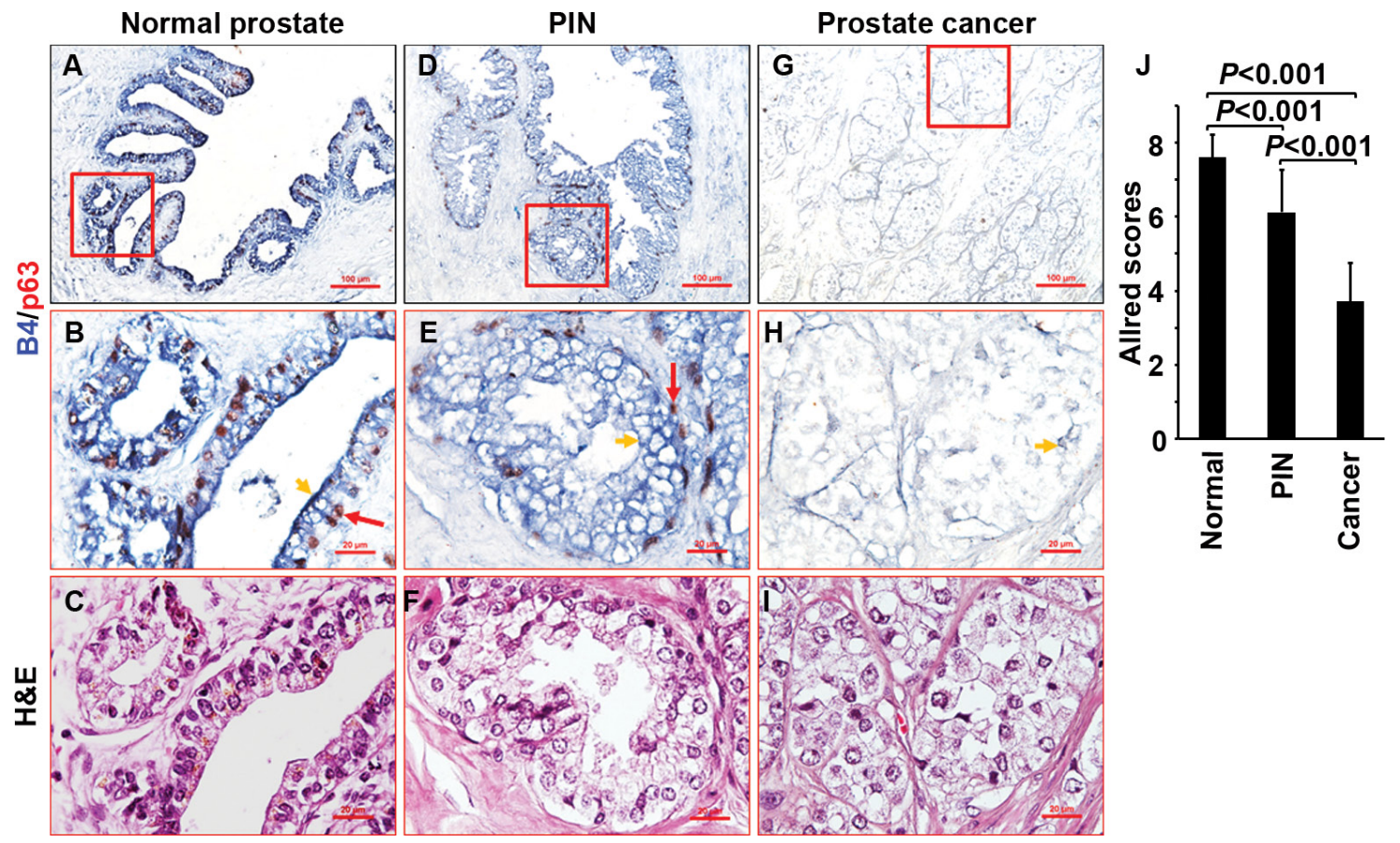

Figure 7: Phosphorylation of IL-17RA is detected in human prostate tissues. (A-I) Human normal prostate, PIN, and prostate cancer tissues were double stained for P-IL-17RA using B4 (arrowheads) and for basal cells using anti-p63 (arrows). (J) Quantification of P-IL-17RA staining. 
T780-phosphorylated IL-17RA. Phosphorylation of IL-17RA at T780 is linked to K48-mediated ubiquitination and proteasome-mediated degradation, as we showed that T780A mutant IL-17RA is less ubiquitinated and degraded compared to wild-type IL-17RA. IL-17RA is also ubiquitinated with K63 ubiquitin, and T780A mutant IL-17RA also showed reduced K63-mediated ubiquitination. The biological significance of K63-ubiquitination of IL-17RA is unknown, though K63-ubiquitination of other proteins has been linked to protein functions [6]. It has also been demonstrated that both K48- and K63-ubiquitinations are associated with endocytosis and degradation of some membrane proteins $[47,48]$.

Phosphorylation of IL-17RA is linked to degradation of IL-17RA. We have demonstrated that total IL-17RA protein levels are increased when IL-17RA phosphorylation is reduced by $\mathrm{LiCl}$ and insulin through inhibiting GSK3 activities. Conversely, when IL-17RA phosphorylation is increased by AZD5363 treatment, the total IL-17RA protein level is reduced. Thus, there is an inverse correlation between IL-17RA and P-IL-17RA levels. We observed that this is true in human prostate and skin tissues. The levels of P-IL-17RA are higher in the normal prostatic glands than prostate cancer. In contrast, the levels of IL-17RA are higher in prostate cancer than in the normal prostatic glands, which is consistent to a previous report [40]. We found that obese mouse prostate tumors expressed higher levels of IL-17RA than lean mice (Figure 1F). We also observed that IL-17RA levels were mainly increased in the epithelial tumor cells, though IL-17RA levels in the stromal cells were also increased in obese mice compared to lean mice (IHC data not shown). In human prostate cancer, it has been shown that GSK $3 \alpha$ is mainly expressed in low-risk prostate cancers and is associated with hormone-dependent androgen receptor (AR)-mediated gene expression, whereas GSK $3 \beta$ is mainly expressed in high-risk prostate cancers and is associated with hormone-independent AR-mediated gene expression $[49,50]$. Knockout either $G s k 3 \alpha$ or $G s k 3 \beta$ can increase the IL-17 responsiveness in mouse embryonic fibroblasts $[33,34]$. However, in mouse prostate tumors, GSK3 $\beta$ levels are higher than GSK3 $\alpha$ levels (Figure 1F), thus GSK3 $\beta$ may play more important roles than GSK3 $\alpha$. It is intriguing to investigate whether there is any link between IL-17RA and AR in the context of GSK3's regulatory functions in prostate cancer. In normal and psoriatic skin tissues, P-IL-17RA is absent in the proliferative keratinocytes, while IL-17RA is present. The levels of IL-17RA are associated to IL-17 responsiveness as shown in our in vitro studies with 293-IL-17RA and HeLa cell lines. Treatment of the cells with insulin increases the levels of IL-17RA and the expression levels of IL-17induced genes, whereas AZD5363 treatment decreases the levels of IL-17RA and the expression levels of IL-17-induced genes.

In summary, our observation that IL-17RA is phosphorylated by GSK3 reveals a new role of GSK3 in the crosstalk between the metabolic pathway and inflammatory pathway. Targeting GSK3, e.g., using melatonin or AZD5363 [33, 34], represents a potential therapeutic approach to suppress IL-17-mediated inflammation that may be applicable to the prevention and treatment of prostate cancer.

\section{MATERIALS AND METHODS}

\section{Reagents}

The antibodies and peptides used are as follows: rabbit anti-human phospho-IL-17RA (T780) polyclonal antibodies (B1, B2, B3, and B4), phosphorylated antigen peptide (C-LTDPH(pT)PYEEEQ) and non-phosphorylated antigen peptide (C-LTDPHTPYEEEQ) were produced through a contract by AbMART (Shanghai) CO., LTD., Shanghai, China. The same antigen peptides and mutant peptide (C-LTDPH(A)PYEEEQ) were independently synthesized by Peptide 2.0 Inc. (Chantilly, VA, USA), which were used for characterization of the antibodies. Rabbit anti-P-Akt (S473), rabbit anti-Akt, rabbit anti-P-GSK3 $\beta$ (S9), rabbit anti-GSK3 $\beta$, rabbit anti-P-GSK3 $\alpha$ (S21), and rabbit anti-GSK3 $\alpha$ antibodies were purchased from Cell Signaling Technology. Mouse anti-GAPDH antibodies were purchased from Millipore Corporation. Mouse anti-Flag antibodies and ANTI-FLAG ${ }^{\circledR}$ M2 Affinity Gel were purchased from Sigma Aldrich. Mouse anti-HA antibodies were purchased from Covance. Rabbit and mouse anti-Ki-67 and anti-IL-17RA (H-168) antibodies were purchased from Santa Cruz Biotechnology. Mouse anti-p63 antibodies were purchased from Biocare Medical.

\section{Plasmids and construction of IL-17RA mutants}

The plasmids used were as follows: pcDNA3.1 expressing human IL-17RA with Flag tag and pcDNA3.1 expressing human Act1 with HA tag were described previously [51] and were kindly provided by Dr. Xiaoxia Li at Cleveland Clinic Lerner Research Institute. Constructs with point mutations and truncations were created by overlapping extension PCR, using the Flag-IL-17RA plasmid as template. The sense strand primers are as follows: IL-17RA-T780A forward: 5'gtcctcacagacccacacgcgccctacgaggaggagcagcgg 3'; IL-17RA $\Delta 781-820$ T780A forward:5' gtcctcacagacccac acgcgecagggaagceggecetgeca 3'; IL-17RA-796A+798A $+800 \mathrm{~A}+801 \mathrm{~A}$ forward: $5^{\prime}$ cagtctgaccagggegccatcgccagg gecgeccegcageccecegag 3'; IL-17RA-Y796A forward: 5' 
cagtctgaccagggegccatctccaggagctcc 3'; IL-17RA-T780A $+\mathrm{Y} 782 \mathrm{~A}+\mathrm{S} 789 \mathrm{~A}+\mathrm{S} 792 \mathrm{~A}$ forward: $5^{\prime}$ gtcctcacagacccaca cgccccegccgaggaggagcagcggcaggecgtgcaggecgaccaggg ctacatc 3'; IL-17RA-S 792A+ Y796A+ S800A forward: $5^{\prime}$ 'cggcagtcagtgcaggecgaccagggegccatctccagggectccecgca geccec 3'; IL17RA-S861A+S865A forward: 5' gcgec cetggtgcgegagcetggegeccaggectgectggccatagaccegc $3^{\prime}$; IL-17RA $\Delta 534-615$ forward:5' gacaggttcgaggaggtgtacggca tcgtgaagcgggegecc 3'; IL-17RA $\Delta 616-728$ forward: 5' ccactgctgcctccgggaaccggcagcagcacccccatggcg 3'; IL-17 RA $\Delta 729-780$ forward: $5^{\prime}$ gaccecgaggactcgeccettgtcetcaca gacccacacacg 3'; IL-17RA $\triangle 343-772$ forward: 5' ctgctcatcg tctgcatggtcctcacagacccacac 3'; IL-17RA-S561A forward: 5' gacaactacctgcgggecccgggeggcaggcag $3^{\prime} ; \quad$ IL-17 RA-S715A forward: 5' ggcgetgggegaaatgcegtcct cttcctccec 3'; IL-17RA-S554A+Y558A+S561A forward: $5^{\prime}$ cgcgtaggggagctggcgggggacaacgccetgcgggeccegggcggca ggcag 3'; IL-17RA-Y591A-S592A-S600 forward: 5' gaatgtgagaacctcgccgccgcagatgaccaggatgccceggccetggacga agaggtg 3'. The antisense primers were their complementary sequences. All of the primers were synthesized by Eurofins Genomics. Mutagenic reactions were performed in $20 \mu \mathrm{l}$ of PCR mix containing $20-40 \mathrm{ng}$ of template DNA, $100 \mathrm{nM}$ primers and $2.5 \mathrm{U}$ Pfx DNA polymerase (Invitrogen). The PCR conditions were: an initial denaturation at $94^{\circ} \mathrm{C}$ for $5 \mathrm{~min}$, followed by 18 cycles of $94^{\circ} \mathrm{C}$ for $1 \mathrm{~min}, 60^{\circ} \mathrm{C}$ for $1 \mathrm{~min}$, and $68^{\circ} \mathrm{C}$ for $12 \mathrm{~min}$ as well as a final extension at $68^{\circ} \mathrm{C}$ for 20 minutes. $1 \mu \mathrm{l}(20 \mathrm{U})$ of DpnI enzyme (New England Biolab) was added to the PCR products at $37^{\circ} \mathrm{C}$ for $2 \mathrm{~h}$. After DpnI digestion, $5 \mu \mathrm{l} \mathrm{PCR}$ products were transformed into $50 \mu \mathrm{l}$ of DH5 $\alpha$ E. coli competent cells (Invitrogen). Then, $250 \mu \mathrm{l}$ of LB medium (Invitrogen) were added for recovery at $37^{\circ} \mathrm{C}$ for $1 \mathrm{~h}$. The transformed bacteria were plated on LB agar (Invitrogen) plates with ampicillin antibiotics. After overnight culture at $37^{\circ} \mathrm{C}$, two or three colonies were cultured for plasmid DNA isolation, using Wizard Plus SV minipreps purification system (Promega). All constructs were confirmed by DNA sequencing (Genewiz, Inc.).

\section{Cell culture, transfection and establishment of stable cell lines}

Human cervical cancer HeLa cell line and human embryonic kidney 293 cell line were obtained from the American Type Culture Collection, Manassas, VA, and were free of mycoplasma contamination. The cells were maintained in Dulbecco's Modified Eagles Medium (DMEM, Mediatech, Inc.) containing $10 \%$ fetal bovine serum (FBS, Mediatech, Inc.) and $100 \mathrm{IU} / \mathrm{ml}$ penicillin/streptomycin in a $37^{\circ} \mathrm{C}, 5 \%$ $\mathrm{CO}_{2}$ humidified incubator. Transient overexpression transfections were performed using Lipofectamine 2000 (Invitrogen) according to the manufacturer's instructions. 293 cells were used to establish cell lines that stably expressed wild-type Flag-IL-17RA, Flag-IL-17RA
T780A mutant, and other mutants. Twenty-four h prior to transfection, 293 cells were seeded at a density of $5.0 \times 10^{5}$ cells/dish in $60-\mathrm{mm}$ dishes. Transfection was performed with $1 \mu \mathrm{g}$ DNA and $4 \mu$ l Lipofectamine 2000 in $150 \mu$ l OptiMEM medium (Invitrogen). One day after transfection, the cells were treated with $500 \mu \mathrm{g} / \mathrm{ml} \mathrm{G} 418$ (Invitrogen) to select for the cells stably expressing the neomycin resistance gene and human IL-17RA. Where indicated, 293 cells were seeded into 60 -mm cell culture dishes with approximately $0.8 \times 10^{6}$ cells/dish. After $24 \mathrm{~h}$ incubation, the cells were treated with $20 \mathrm{mM} \mathrm{LiCl}$ (Sigma Aldrich), $10 \mu \mathrm{M}$ MG132 (Sigma Aldrich), and/or $50 \mu \mathrm{g} / \mathrm{ml}$ cycloheximide (inhibitor of protein translation, Sigma Aldrich) for the indicated time periods. Then, the cell lysates were used for Western blot analysis.

\section{Mass spectrometry (MS) phosphopeptide mapping}

293 cells were transiently transfected with pcDNA 3.1 expressing Flag-IL-17RA. 24 h later, Flag-IL-17RA protein was purified from whole cell lysate, using ANTI-FLAG ${ }^{\circledR}$ M2 Affinity Gel (Sigma Aldrich) according to the manufacturer's instructions. The protein was separated on sodium dodecyl sulfate-polyacrylamide gel electrophoresis (SDS-PAGE) gel and stained with Coomassie Blue. The band corresponding to IL-17 RA band as detected by Western blot was excised from the gel and analyzed by MS. The gel pieces containing IL-17RA protein were dehydrated with acetonitrile for $10 \mathrm{~min}$, vacuum dried, rehydrated with $5 \mathrm{mM}$ Tris (2-carboxyethyl) phosphine hydrochloride in $25 \mathrm{mM}$ ammonium bicarbonate $(\mathrm{pH} 8.5)$ at $37^{\circ} \mathrm{C}$ for $1 \mathrm{~h}$, and subsequently alkylated with $20 \mathrm{mM}$ iodoacetamide in $25 \mathrm{mM}$ ammonium bicarbonate $(\mathrm{pH} 8.5)$ at room temperature for $1 \mathrm{~h}$. The pieces were dehydrated with acetonitrile for $10 \mathrm{~min}$, dried, and rehydrated with $35 \mu \mathrm{l}$ of sequencing grade, modified trypsin $(12.5 \mathrm{ng} / \mu \mathrm{l})$ (Promega) in $25 \mathrm{mM}$ ammonium bicarbonate $(\mathrm{pH} 8.5)$ at $37^{\circ} \mathrm{C}$ for overnight. Following the digestion, tryptic peptides were extracted three times with $50 \%$ acetonitrile containing $5 \%$ formic acid for 15 min each time with moderate sonication. The extracted solutions were pooled and evaporated to dryness under vacuum. To facilitate liquid chromatography (LC)-MS/MS characterization of phosphorylation sites, $\mathrm{TiO} 2$ based immobilized metal ion affinity chromatography (IMAC) was used to enrich the signals of phosphopeptides prior to MS. This enabled us to detect phosphopeptides with higher sensitivity [52]. Briefly, the peptides were dissolved in $20 \mu 1$ of $5 \%$ formic acid plus $10 \%$ acetonitrile. The phosphopeptides were enriched using TiO2 TopTip (Glygen Inc.). The bound peptides were eluted with $0.5 \% \mathrm{NH}_{3} \mathrm{OH}$ followed by acidification with $10 \%$ formic acid. Both flow-through and eluent were reconstituted in $50 \mu \mathrm{l} 5 \%$ formic acid. LC-MS/MS analysis was 
performed on an integrated QSTAR XL nanoLC-MS/MS system (ABSCIEX) comprised of three micro-pumps with an autosampler, a stream select module configured for precolumn plus analytical capillary column, and a QSTAR XL mass spectrometer fitted with nano-sprayer III, operated under both Analyst 1.1 and MassLynx 4.0 control with a contact closure. Injected samples were first trapped and desalted isocratically on an Everest C18 precolumn ( $5 \mu \mathrm{m}, 500 \mu \mathrm{m}$ ID X 15 mm, Grace, Deerfield, IL) for 6 min with $0.1 \%$ formic acid delivered by the auxiliary pump at $40 \mu \mathrm{l} / \mathrm{min}$, after which the peptides were eluted off from the precolumn and separated on an analytical C18 capillary column $(15 \mathrm{~cm} \times 100 \mu \mathrm{m}$ i.D., packed with $3 \mu \mathrm{m}$ Jupitor C18 particles, Phenomenex, Torrance, CA, USA) connected inline to the mass spectrometer, at $300 \mathrm{nl} / \mathrm{min}$ using a 50 min fast gradient of $5 \%$ to $60 \%$ acetonitrile in $0.1 \%$ formic acid and $0.0075 \%$ trifluoroacetic acid. MS/MS peak list was created from raw MS data using an Analyst "script" Mascot.dll. Then the peak list files were used to query human IL-17RA protein sequence using the MASCOT 2.4 from Matrix Science (London, UK) with the following parameters: peptide mass tolerance, 0.3 Da; $\mathrm{MS} / \mathrm{MS}$ ion mass tolerance, $0.3 \mathrm{Da}$; allowed up to two missed cleavage; variable modifications considered were methionine oxidation, cysteine carboxyamidomethylation, phosphorylation (STY) with neutral losses of phosphoric acid and deamindation (N,Q). Only significant hits as defined by Mascot probability analysis were considered initially. Error tolerant search was used to assess the total sequence coverage of the protein. The phosphopeptides were identified based on neutral loss of $98 \mathrm{Da}$ (corresponding to phosphoric acid) as a marker ion as well as at least 3 continuous ion series ( $y$ or b).

\section{Cell labeling with ${ }^{32} \mathrm{P}$ orthophosphate}

Approximately 2 million 293 cells were cultured in 100-mm cell culture dishes for overnight and transfected or co-transfected with $4 \mu \mathrm{g}$ each of the indicated plasmids using the Lipofectamine 2000 according to the manufacturer's instructions. Two days after transfection, the cells were washed with phosphatefree DMEM and incubated in $5 \mathrm{ml}$ phosphate-free DMEM medium containing $200 \mu \mathrm{Ci}^{32} \mathrm{P}$ orthophosphate (MP Biomedical) for $4 \mathrm{~h}$. The cells were washed with PBS twice and then lysed in $0.35 \mathrm{ml}$ RIPA buffer (50 mM sodium fluoride, 0.5\% Igepal CA-630 [NP-40], 10 $\mathrm{mM}$ sodium phosphate, $150 \mathrm{mM}$ sodium chloride, $25 \mathrm{mM}$ Tris $\mathrm{pH}$ 8.0, $1 \mathrm{mM}$ phenylmethylsulfonyl fluoride, $2 \mathrm{mM}$ ethylenediaminetetraacetic acid [EDTA], $1.2 \mathrm{mM}$ sodium vanadate) supplementary with protease inhibitor cocktail (Sigma Aldrich). $0.3 \mathrm{ml}$ of the extract was used for immunoprecipitation (IP) using ANTI-FLAG ${ }^{\circledR}$ M2 Affinity Gel. Where indicated, an aliquot of IP products was treated with 20 units of calf intestine alkaline phosphatase (CIP, New England Biolab) at $37^{\circ} \mathrm{C}$ for $2 \mathrm{~h}$. The samples were resolved by SDS-PAGE, transferred onto polyvinylidene difluoride (PVDF) membrane (BIO-RAD), and visualized by autoradiography followed by Western blot analysis.

\section{Western blot (or immunoblot) and dot blot analyses}

Cell lysates or immunoprecipitates were subjected to $10 \%$ SDS-PAGE and transferred to PVDF membrane. For dot blot analysis, $1 \mu$ peptide was printed onto nitrocellulose membrane (BIO-RAD) and air dried. The membranes were blocked with 5\% nonfat dry milk in TBST buffer (25 mM Tris-HCl, $125 \mathrm{mM} \mathrm{NaCl}$, and $0.1 \%$ Tween 20 ) for $1 \mathrm{~h}$ and probed with the indicated primary antibodies overnight. After washing 3 times with TBST buffer, the membranes were incubated with IRDye $800 \mathrm{CW}$ - or IRDye 680RD-conjugated secondary antibodies (LI-COR Biosciences) for $1 \mathrm{~h}$. The results were visualized using an Odyssey Infrared Imager (LICOR Biosciences).

\section{In vitro kinase assay}

For human peptides, $5 \mu \mathrm{g}$ non-phosphorylated peptides were incubated with or without $1 \mu \mathrm{l}(0.35 \mu \mathrm{g})$ of recombinant human GSK3 $\alpha$ (Invitrogen) or $1 \mu \mathrm{l}(500$ units) recombinant human or rabbit GSK3 $\beta$ (R \& D Systems or New England Biolab) in $9 \mu$ GSK3 kinase buffer (New England Biolab) with or without $200 \mu \mathrm{M}$ ATP (New England Biolab) at $30^{\circ} \mathrm{C}$ for $1 \mathrm{~h}$. One $\mu \mathrm{l}$ sample was printed onto nitrocellulose membrane, air dried, and probed with anti-phospho-IL-17RA antibodies. For mouse peptides, $14 \mu \mathrm{g}$ non-phosphorylated peptide was incubated with or without $2 \mu \mathrm{l}(0.70 \mu \mathrm{g})$ of active recombinant GSK $3 \alpha$ or $2 \mu \mathrm{l} \mathrm{GSK3} \beta$ (1000 units) in $18 \mu \mathrm{l}$ GSK3 kinase buffer with $4 \mu \mathrm{Ci} \gamma-{ }^{32} \mathrm{P}$-ATP at $30^{\circ} \mathrm{C}$ for $1 \mathrm{~h}$. About $20 \mu \mathrm{l}$ samples were added to the filter (Microcon$10 \mathrm{kDa}$ Centrifugal Unit, Millipore) and centrifuged at $8000 \times \mathrm{g}$ for $30 \mathrm{~min}$. This centrifugation was needed to remove ${ }^{32} \mathrm{P}$-labeled GSK3 due to auto-activation of the recombinant GSK3 during the kinase assay, as the molecular weight of GSK3 was larger than $10 \mathrm{kDa}$ and hence could not pass through the $10 \mathrm{kDa}$-filter of Microcon-10kDa Centrifugal Units. Negative controls with GSK3 and ATP, but without the peptides, were included to rule out the possibility that any degraded/ fragmented ${ }^{32} \mathrm{P}$-labeled GSK3 might be filtered through. Two $\mu$ of the filtrate (containing the molecules smaller than $10 \mathrm{kDa}$, including the peptides) were dot blotted onto a nitrocellulose membrane, air dried, and washed 3 times (10 minutes each) with $1 \%$ phosphoric acid solution to remove free $\gamma-{ }^{32} \mathrm{P}$-ATP. The membrane was then analyzed by autoradiography. For full-length mouse IL-17RA, HA-tagged mouse IL-17RA [53] was first expressed in 293 cells and purified using IP. Aliquots of mouse IL-17RA were treated with recombinant human GSK3 $\alpha$ or 
recombinant human or rabbit GSK3 $\beta$ as described above. The samples were analyzed using Western blot analysis with B4 antibody.

\section{Immunoprecipitation (IP)}

293 cells were cultured in 100-mm cell culture dishes for overnight and transfected or co-transfected with $4 \mu \mathrm{g}$ each of the indicated plasmids using Lipofectamine 2000 according to the manufacturer's instructions. Two days after transfection, proteins were extracted from the cells using RIPA lysis buffer. The extracts $(0.3 \mathrm{ml}$ each $)$ were incubated with $15 \mu \mathrm{l}$ ANTI-FLAG ${ }^{\circledR}$ M2 Affinity Gel or $1 \mu \mathrm{g}$ of the indicated primary antibody plus $20 \mu \mathrm{l}$ of protein A sepharose CL-4B beads (GE Healthcare Bio-Sciences $\mathrm{AB}$ ) overnight at $4^{\circ} \mathrm{C}$ with rotation. The samples were washed 3 times with phosphate-buffered saline (PBS) and boiled in $20 \mu \mathrm{l}$ of SDS sample buffer for Western blot (WB) analysis, also called immunoblot (IB) analysis.

\section{Ubiquitination assays}

Rabbit anti-K48-linkage specific polyubiquitin and anti-K63-linkage specific polyubiquitin monoclonal antibodies were purchased from Cell Signaling Technology. Mouse anti-HA antibodies were purchased from Covance. Plasmid pcDNA3.1-HA-Ubiquitin (HA-Ub, expressing wild-type ubiquitin) was provided by Dr. Hua Lu (Tulane University). Plasmids pRK5-HA -Ubiquitin-K48 (HA-K48, expressing ubiquitin with K48 only and other lysines were mutated to arginines) and pRK5-HA-Ubiquitin-K63 (HA-K63, expressing ubiquitin with K63 only and other lysines were mutated to arginines) were obtained from Addgene. Two million 293 cells were transfected or co-transfected with $4 \mu \mathrm{g}$ each of the indicated plasmids using the Lipofectamine 2000 (Invitrogen) according to the manufacturer's instructions. Twenty-four $\mathrm{h}$ post-transfection, the cells were treated with or without MG132 for $6 \mathrm{~h}$. Proteins were extracted from the cells and used for IP using ANTI-FLAG ${ }^{\circledR}$ M2 Affinity Gel. The immunoprecipitates were subjected to Western blot analysis with the indicated antibodies.

\section{Quantitative real-time PCR (qRT-PCR) analysis}

Human HeLa and 293-IL-17RA stable cells were treated with $2 \mu \mathrm{M}$ AZD5363 (Selleck Chemicals, Inc.), $50 \mathrm{ng} / \mathrm{ml}$ insulin (Sigma Aldrich), and/or $20 \mathrm{ng} / \mathrm{ml}$ recombinant human IL-17A (R \& D Systems) for $2 \mathrm{~h}$. Mouse embryonic fibroblasts (MEFs) with wild-type $G s k 3 \beta^{+/+}$or knockout $G s k 3 \beta^{-/-}$were treated with $20 \mathrm{ng} / \mathrm{ml}$ recombinant mouse IL-17A, IL-17F, IL-17C, or IL-17E (R \& D Systems) for $2 \mathrm{~h}$. RNA was isolated for qRT-PCR analysis as described previously [33].

\section{Human tissue specimens}

Human prostate and skin tissue samples were provided by Ochsner Clinic Foundation (for prostate tissues) and the Affiliated Hospital of Guangdong Medical College (for skin tissues) with approval of the Institutional Review Boards of Ochsner Clinic Foundation and Guangdong Medical College, respectively. A total of 56 prostate tissues (including prostate cancer with concurrent PIN lesions and para-tumor normal prostate tissues), 17 normal skin tissues, and 17 psoriasis skin tissues were used. These samples were archived and de-identified. They were fixed with $4 \%$ phosphate-buffered paraformaldehyde, embedded in paraffin blocks, and cut into $4-\mu \mathrm{m}$ sections. The sections were de-paraffinized in xylene, hydrated using graded alcohols, and stained with hematoxylin and eosin (H \& E) for histopathologic confirmation by two pathologists (W.W.T. and A.R.W.).

\section{Immunohistochemical (IHC) and immunofluorescence (IF) staining}

IHC and IF double staining were conducted as described previously [17]. The antibodies used were rabbit anti-phospho-IL-17RA (B4) (1:500 dilution), rabbit anti-IL-17RA (1:100 dilution, H-168/sc-30175, Santa Cruz Biotechnology), mouse anti-Ki-67 (1:500 dilution, sc-23900, Santa Cruz Biotechnology), mouse anti-p63 (1:100 dilution, Biocare Medical), and Cy3-conjugated anti-mouse IgG and DyLight 488-conjugated anti-rabbit IgG (Jackson ImmunoResearch Laboratories). IHC double staining was conducted using a Vectastain ${ }^{\circledR} \mathrm{ABC}$ kit (Vector Laboratories) according to manufacturer's instructions.

\section{Animal models}

Animal study was approved by the Animal Care and Use Committee of Tulane University. The breeding and genotyping protocols have been described previously, using Pten ${ }^{\text {loxp/loxp }}$ mice (strain C;129S4-Pten ${ }^{\text {tm1Hwu/J) and }}$ PB-Cre4 mice (strain B6.Cg-Tg(Pbsn-cre)4Prb) that created Pten conditional knockout in mouse prostates with prostate cancer formation [17, 37]. Briefly, PB-Cre4 male mice were crossed to $P$ ten ${ }^{\text {loxp/loxp }}$ female mice to produce Pten ${ }^{\text {loxp} / \text { WT }} ;$ Cre $^{+}$male breeders; then, Pten ${ }^{\text {loxp} /}$ ${ }^{\text {WT}}$; $\mathrm{Cre}^{+}$male mice were crossed to $P$ ten $^{\text {loxp/loxp }}$ female mice to produce Pten $^{\text {loxp/loxp}} ; \mathrm{Cre}^{+}$male mice. At 3 weeks of age after genotyping and weaning, male mice with Pten $^{\text {loxp} / ~}$ loxp; $\mathrm{Cre}^{+}$genetic background were randomized into a group $(n=10)$ fed with standard chow diet $(13.2 \%$ calories by fat, cat\# 5053, LabDiet, Brentwood, MO) or a group $(n=10)$ fed with high-fat diet $(60 \%$ calories by fat, cat\# D12492, Research Diets, New Brunswick, NJ). Animal body weight was measured weekly. At 30 
weeks of age, animals were euthanized. Approximately $0.7 \mathrm{ml}$ blood sample from each mouse was taken and transferred to a pre-coated EDTA vial (containing $0.4 \mathrm{mg}$ ethylenediaminetetraacetic acid). The blood was immediately centrifuged and the plasma was stored at $-80^{\circ} \mathrm{C}$ freezer until analysis. The plasma levels of IL-17A, insulin, IGF1, and leptin were measured using enzymelinked immunosorbant assay (ELISA) kits (RayBiotech, Inc.) according to the manufacturer's instructions. Weights of whole animal, genitourinary (GU) block, inguinal fat, and epididymal fat were measured. Pathological examination of PIN and invasive prostate cancer, Western blot analysis of protein levels, and real-time quantitative PCR analysis of mRNA levels in the prostate tissues were performed as described previously [17].

\section{Statistical analysis}

All in vitro experiments were replicated three times if not indicated otherwise. Statistical significance was determined by one-way analysis of variance (ANOVA) and Tukey's tests for multiple comparisons, or unpaired Student's $t$ test for quantitative data with the assumption of normal distribution of data and equal sample variance, or by Kruskal-Wallis test for qualitative data. The tests were two-sided. A $P$ value $<0.05$ was considered statistically significant. Sample sizes were selected on the basis of preliminary results to ensure an adequate power. Animal number estimate was based on our previous studies $[17,18]$. All cells and mice studied were included for statistical analysis. All data points were included. After genotyping, animals were randomized into either high fat-diet or standard chow-diet groups by flipping a coin. The examiners were blinded to the grouping of animals when performing pathological examinations.

\section{ACKNOWLEDGMENTS}

The authors thank Dr. Xiaoxia Li at Cleveland Clinic Lerner Research Institute for providing human Flag-IL-17RA and HA-Act1 plasmids, Dr. Sarah Gaffen at University of Pittsburgh for providing mouse HA-IL-17RA plasmid, Dr. James R. Woodgett (Mount Sinai Hospital and the Samuel Lunenfeld Research Institute, Toronto, Ontario, Canada M5G $1 \times 5$ ) for providing the $G s k 3 \beta$ wild-type and knockout cell lines, and Dr. Hua Lu (Tulane University) for providing pcDNA3.1-HA-Ubiquitin plasmid. Tulane Cancer Center and Louisiana Cancer Research Consortium core facilities were used in these studies.

\section{GRANT SUPPORT}
Z.Y. was partially supported by National Institutes of Health (R01CA174714 and P20GM103518),

Department of Defense (W81XWH-14-1-0050, W81XWH-14-1-0149, W81XWH-14-1-0458, and W81XWH-15-1-0444 (PI: Feng Chen; Co-I: Z.Y.)), the Developmental Fund of Tulane Cancer Center (TCC), Louisiana Cancer Research Consortium (LCRC) Fund, and Tulane's Institute of Integrated Engineering for Health and Medicine (TI2EHM). W.Z. and K.Z. were partially supported by National Institute on Minority Health and Health Disparities (NIMHD)/NIH (2G12MD007595, PIs: Gene D'Amour and Guangdi Wang). The funding agencies had no role in the design, collection, analysis, and interpretation of data, in the writing of the manuscript, and in the decision to submit the manuscript for publication. The content of this article is solely the responsibility of the authors and does not necessarily represent the official views of the National Institutes of Health or the Department of Defense.

\section{CONFLICTS OF INTERESTS}

The authors declared no conflicts of interests.

\section{REFERENCES}

1. Moseley TA, Haudenschild DR, Rose L, Reddi AH. Interleukin-17 family and IL-17 receptors. Cytokine Growth Factor Rev. 2003; 14:155-74.

2. Gaffen SL, Jain R, Garg AV, Cua DJ. The IL-23-IL-17 immune axis: from mechanisms to therapeutic testing. Nat Rev Immunol. 2014; 14:585-600.

3. Shi Y, Ullrich SJ, Zhang J, Connolly K, Grzegorzewski KJ, Barber MC, Wang W, Wathen K, Hodge V, Fisher CL, Olsen H, Ruben SM, Knyazev I, et al. A novel cytokine receptor-ligand pair. Identification, molecular characterization, and in vivo immunomodulatory activity. J Biol Chem. 2000; 275:19167-76.

4. Reynolds JM, Lee YH, Shi Y, Wang X, Angkasekwinai P, Nallaparaju KC, Flaherty S, Chang SH, Watarai H, Dong C. Interleukin-17B Antagonizes Interleukin-25-Mediated Mucosal Inflammation. Immunity. 2015; 42:692-703.

5. McAleer JP, Kolls JK. Directing traffic: IL-17 and IL-22 coordinate pulmonary immune defense. Immunol Rev. 2014; 260:129-44.

6. Liu C, Qian W, Qian Y, Giltiay NV, Lu Y, Swaidani S, Misra S, Deng L, Chen ZJ, Li X. Act1, a U-box E3 ubiquitin ligase for IL-17 signaling. Sci Signal. 2009; 2:ra63.

7. Onishi RM, Gaffen SL. Interleukin-17 and its target genes: mechanisms of interleukin-17 function in disease. Immunology. 2010; 129:311-21.

8. Van Kooten C, Boonstra JG, Paape ME, Fossiez F, Banchereau J, Lebecque S, Bruijn JA, De Fijter JW, Van Es LA, Daha MR. Interleukin-17 activates human renal epithelial cells in vitro and is expressed during renal allograft rejection. J Am Soc Nephrol. 1998; 9:1526-34. 
9. Antonysamy MA, Fanslow WC, Fu F, Li W, Qian S, Troutt AB, Thomson AW. Evidence for a role of IL-17 in organ allograft rejection: IL-17 promotes the functional differentiation of dendritic cell progenitors. J Immunol. 1999; 162:577-84.

10. Wu S, Rhee KJ, Albesiano E, Rabizadeh S, Wu X, Yen HR, Huso DL, Brancati FL, Wick E, McAllister F, Housseau F, Pardoll DM, Sears CL. A human colonic commensal promotes colon tumorigenesis via activation of $\mathrm{T}$ helper type 17 T cell responses. Nat Med. 2009; 15:1016-22.

11. Chae WJ, Bothwell AL. IL-17F deficiency inhibits small intestinal tumorigenesis in ApcMin $/+$ mice. Biochem Biophys Res Commun. 2011; 414:31-6.

12. Chae WJ, Gibson TF, Zelterman D, Hao L, Henegariu O, Bothwell AL. Ablation of IL-17A abrogates progression of spontaneous intestinal tumorigenesis. Proc Natl Acad Sci U S A. 2010; 107:5540-4.

13. Hyun YS, Han DS, Lee AR, Eun CS, Youn JH, Kim HY. Role of IL-17A in the development of colitis-associated cancer. Carcinogenesis. 2012.

14. Xiao M, Wang C, Zhang J, Li Z, Zhao X, Qin Z. IFNgamma promotes papilloma development by up-regulating Th17associated inflammation. Cancer Res. 2009; 69:2010-7.

15. Wang L, Yi T, Zhang W, Pardoll DM, Yu H. IL-17 enhances tumor development in carcinogen-induced skin cancer. Cancer Res. 2010; 70:10112-20.

16. Novitskiy SV, Pickup MW, Gorska AE, Owens P, Chytil A, Aakre M, Wu H, Shyr Y, Moses HL. TGF-beta Receptor II Loss Promotes Mammary Carcinoma Progression by Th17 Dependent Mechanisms. Cancer Discov. 2011; 1:430-41.

17. Zhang Q, Liu S, Ge D, Xue Y, Xiong Z, Abdel-Mageed AB, Myers L, Hill SM, Rowan BG, Sartor O, Melamed J, Chen Z, You Z. Interleukin-17 promotes formation and growth of prostate adenocarcinoma in mouse models. Cancer Res. 2012; 72:2589-99.

18. Zhang Q, Liu S, Xiong Z, Wang AR, Myers L, Melamed J, Tang WW, You Z. Interleukin-17 promotes development of castration-resistant prostate cancer potentially through creating an immunotolerant and pro-angiogenic tumor microenvironment. Prostate. 2014; 74:869-79.

19. Chang SH, Mirabolfathinejad SG, Katta H, Cumpian AM, Gong L, Caetano MS, Moghaddam SJ, Dong C. T helper 17 cells play a critical pathogenic role in lung cancer. Proc Natl Acad Sci U S A. 2014; 111:5664-9.

20. Xu B, Guenther JF, Pociask DA, Wang Y, Kolls JK, You Z, Chandrasekar B, Shan B, Sullivan DE, Morris GF. Promotion of lung tumor growth by interleukin-17. Am J Physiol Lung Cell Mol Physiol. 2014; 307:L497-508.

21. McAllister F, Bailey JM, Alsina J, Nirschl CJ, Sharma R, Fan H, Rattigan Y, Roeser JC, Lankapalli RH, Zhang H, Jaffee EM, Drake CG, Housseau F, et al. Oncogenic Kras activates a hematopoietic-to-epithelial IL-17 signaling axis in preinvasive pancreatic neoplasia. Cancer Cell. 2014; 25:621-37.
22. Magalhaes I, Pingris K, Poitou C, Bessoles S, Venteclef N, Kiaf B, Beaudoin L, Da Silva J, Allatif O, Rossjohn J, Kjer-Nielsen L, McCluskey J, Ledoux S, et al. Mucosalassociated invariant $\mathrm{T}$ cell alterations in obese and type 2 diabetic patients. J Clin Invest. 2015; 125:1752-62.

23. Saxena A, Desbois S, Carrie N, Lawand M, Mars LT, Liblau RS. Tc17 CD8+ T cells potentiate Th1-mediated autoimmune diabetes in a mouse model. J Immunol. 2012; 189:3140-9.

24. Lim H, Kim YU, Sun H, Lee JH, Reynolds JM, Hanabuchi S, $\mathrm{Wu} \mathrm{H}$, Teng BB, Chung Y. Proatherogenic conditions promote autoimmune $\mathrm{T}$ helper 17 cell responses in vivo. Immunity. 2014; 40:153-65.

25. Liu ZD, Wang L, Lu FH, Pan H, Zhao YX, Wang SJ, Sun SW, Li CL, Hu XL. Increased Th17 cell frequency concomitant with decreased Foxp3+ Treg cell frequency in the peripheral circulation of patients with carotid artery plaques. Inflamm Res. 2012; 61:1155-65.

26. Smith E, Prasad KM, Butcher M, Dobrian A, Kolls JK, Ley K, Galkina E. Blockade of interleukin-17A results in reduced atherosclerosis in apolipoprotein E-deficient mice. Circulation. 2010; 121:1746-55.

27. Hill JO, Wyatt HR, Reed GW, Peters JC. Obesity and the environment: where do we go from here? Science. 2003; 299:853-5.

28. Flegal KM, Carroll MD, Kit BK, Ogden CL. Prevalence of obesity and trends in the distribution of body mass index among US adults, 1999-2010. JAMA. 2012; 307:491-7.

29. Cohen DH, LeRoith D. Obesity, type 2 diabetes, and cancer: the insulin and IGF connection. Endocr Relat Cancer. 2012; 19:F27-45.

30. Hotamisligil GS. Inflammation and metabolic disorders. Nature. 2006; 444:860-7.

31. Sumarac-Dumanovic M, Stevanovic D, Ljubic A, Jorga J, Simic M, Stamenkovic-Pejkovic D, Starcevic V, Trajkovic V, Micic D. Increased activity of interleukin-23/ interleukin-17 proinflammatory axis in obese women. Int $\mathrm{J}$ Obes (Lond). 2009; 33:151-6.

32. Cross DA, Alessi DR, Cohen $\mathrm{P}$, Andjelkovich $\mathrm{M}$, Hemmings BA. Inhibition of glycogen synthase kinase- 3 by insulin mediated by protein kinase B. Nature. 1995; 378:785-9.

33. Ge D, Dauchy RT, Liu S, Zhang Q, Mao L, Dauchy EM, Blask DE, Hill SM, Rowan BG, Brainard GC, Hanifin JP, Cecil KS, Xiong Z, et al. Insulin and IGF1 enhance IL-17-induced chemokine expression through a GSK3Bdependent mechanism: a new target for melatonin's antiinflammatory action. J Pineal Res. 2013; 55:377-87.

34. Chen C, Zhang Q, Liu S, Lambrechts M, Qu Y, You Z. AZD5363 inhibits inflammatory synergy between interleukin-17 and insulin/insulin-like growth factor 1 . Front Oncol. 2014; 4:343.

35. Shen F, Li N, Gade P, Kalvakolanu DV, Weibley T, Doble B, Woodgett JR, Wood TD, Gaffen SL. IL-17 receptor 
signaling inhibits C/EBPbeta by sequential phosphorylation of the regulatory 2 domain. Sci Signal. 2009; 2:ra8.

36. Calle EE, Rodriguez C, Walker-Thurmond K, Thun MJ. Overweight, obesity, and mortality from cancer in a prospectively studied cohort of U.S. adults. N Engl J Med. 2003; 348:1625-38.

37. Wang S, Gao J, Lei Q, Rozengurt N, Pritchard C, Jiao J, Thomas GV, Li G, Roy-Burman P, Nelson PS, Liu X, Wu H. Prostate-specific deletion of the murine Pten tumor suppressor gene leads to metastatic prostate cancer. Cancer Cell. 2003; 4:209-21.

38. Kobayashi N, Barnard RJ, Said J, Hong-Gonzalez J, Corman DM, Ku M, Doan NB, Gui D, Elashoff D, Cohen P, Aronson WJ. Effect of low-fat diet on development of prostate cancer and Akt phosphorylation in the Hi-Myc transgenic mouse model. Cancer Res. 2008; 68:3066-73.

39. Blando J, Moore T, Hursting S, Jiang G, Saha A, Beltran L, Shen J, Repass J, Strom S, DiGiovanni J. Dietary energy balance modulates prostate cancer progression in Hi-Myc mice. Cancer Prev Res (Phila). 2011; 4:2002-14.

40. Steiner GE, Newman ME, Paikl D, Stix U, Memaran-Dagda N, Lee C, Marberger MJ. Expression and function of pro-inflammatory interleukin IL-17 and IL-17 receptor in normal, benign hyperplastic, and malignant prostate. Prostate. 2003; 56:171-82.

41. Bulek K, Liu C, Swaidani S, Wang L, Page RC, Gulen MF, Herjan T, Abbadi A, Qian W, Sun D, Lauer M, Hascall V, Misra $\mathrm{S}$, et al. The inducible kinase IKKi is required for IL-17-dependent signaling associated with neutrophilia and pulmonary inflammation. Nat Immunol. 2011; 12:844-52.

42. Qu F, Gao H, Zhu S, Shi P, Zhang Y, Liu Y, Jallal B, Yao Y, Shi Y, Qian Y. TRAF6-dependent Act1 phosphorylation by the IkappaB kinase-related kinases suppresses interleukin17-induced NF-kappaB activation. Mol Cell Biol. 2012; 32:3925-37.

43. Sfanos KS, Bruno TC, Maris $\mathrm{CH}, \mathrm{Xu} \mathrm{L}$, Thoburn CJ, DeMarzo AM, Meeker AK, Isaacs WB, Drake CG. Phenotypic analysis of prostate-infiltrating lymphocytes reveals TH17 and Treg skewing. Clin Cancer Res. 2008; 14:3254-61.
44. Vykhovanets EV, Maclennan GT, Vykhovanets OV, Gupta S. IL-17 Expression by macrophages is associated with proliferative inflammatory atrophy lesions in prostate cancer patients. Int J Clin Exp Pathol. 2011; 4:552-65.

45. You Z, Dong Y, Kong X, Zhang Y, Vessella RL, Melamed J. Differential expression of IL-17RC isoforms in androgendependent and androgen-independent prostate cancers. Neoplasia. 2007; 9:464-70.

46. Ratner M. IL-17-targeting biologics aim to become standard of care in psoriasis. Nat Biotechnol. 2015; 33:3-4.

47. Marx C, Held JM, Gibson BW, Benz CC. ErbB2 trafficking and degradation associated with K48 and K63 polyubiquitination. Cancer Res. 2010; 70:3709-17.

48. Zhang L, Xu M, Scotti E, Chen ZJ, Tontonoz P. Both K63 and K48 ubiquitin linkages signal lysosomal degradation of the LDL receptor. J Lipid Res. 2013; 54:1410-20.

49. Darrington RS, Campa VM, Walker MM, BengoaVergniory N, Gorrono-Etxebarria I, Uysal-Onganer P, Kawano Y, Waxman J, Kypta RM. Distinct expression and activity of GSK-3alpha and GSK-3beta in prostate cancer. Int J Cancer. 2012; 131:E872-83.

50. Li B, Thrasher JB, Terranova P. Glycogen synthase kinase-3: A potential preventive target for prostate cancer management. Urol Oncol. 2015; 33:456-63.

51. Qian Y, Liu C, Hartupee J, Altuntas CZ, Gulen MF, Jane-Wit D, Xiao J, Lu Y, Giltiay N, Liu J, Kordula T, Zhang QW, Vallance B, et al. The adaptor Act1 is required for interleukin 17-dependent signaling associated with autoimmune and inflammatory disease. Nat Immunol. 2007; $8: 247-56$.

52. Zheng XD, Lee RT, Wang YM, Lin QS, Wang Y. Phosphorylation of Rga2, a Cdc42 GAP, by CDK/Hgc1 is crucial for Candida albicans hyphal growth. EMBO J. 2007; 26:3760-9.

53. Maitra A, Shen F, Hanel W, Mossman K, Tocker J, Swart D, Gaffen SL. Distinct functional motifs within the IL-17 receptor regulate signal transduction and target gene expression. Proc Natl Acad Sci U S A. 2007; 104:7506-11. 